\title{
Prevalence and correlates of non-fatal suicidal behaviour among South Africans
}

\author{
Sean Joe, Dan J. Stein, Soraya Seedat, Allen Herman and David R. Williams
}

\begin{abstract}
Summary
We examined nationally representative data from the 2002-2004 South Africa Stress and Health Study, a national household probability sample of 4351 persons aged 18 years and older: $9.1 \%$ of respondents reported lifetime suicide ideation, $3.8 \%$ a plan and $2.9 \%$ an attempt. Among four ethnic groups, the coloured ${ }^{a}$ group had the
\end{abstract}

highest lifetime prevalence for attempts (7.1\%). Those at higher risk of suicide attempts had one or more DSM-IV disorders

\section{Declaration of interest}

None. Funding detailed in Acknowledgements.
Suicide is becoming a worldwide public health issue. ${ }^{2,3}$ Although there is a wealth of research literature on suicide and non-fatal suicidal behaviour in high-income countries, ${ }^{4-7}$ information on the prevalence and trends of suicide and non-fatal suicidal behaviour in less affluent countries is often scarce. In South Africa there is no single primary data source for nationally representative information on non-fatal suicide behaviour. ${ }^{8}$ National estimates of the lifetime prevalence and correlates of suicide ideation, planning and attempts among the people of South Africa, including specific cultural groups, are reported here for the first time, using data recently collected for the World Health Organization (WHO) World Mental Health Survey. ${ }^{9}$

\section{Method}

The South Africa Stress and Health Study (SASH), which collected data between January 2002 and June 2004, was a national probability sample of 4351 adult South Africans living in households or hostel quarters. ${ }^{10}$ Hostel quarters were included to maximise coverage of young working-age men. The overall response rate was $85.5 \%$. The Composite International Diagnostic Interview $(\mathrm{CIDI})^{11}$ version 3.0 was used to assess suicidality (lifetime ideation, planning and attempts) and the presence of DSM-IV diagnosis in four categories: anxiety, mood, impulse-control and substance use disorder. ${ }^{12}$ The translation of the English version of the CIDI into the six other languages used in the SASH was carried out according to WHO recommendations.

All analyses were done using the SAS version 9.1.3 software package. Discrete-time survival analysis with time-varying covariates was used to study the risk factors of lifetime suicide ideation, plans and attempts. ${ }^{13}$ The data were weighted to adjust for the stratified multistage sample design, differential probability of selection within households as a function of household size and clustering of the data, and for differential non-response. A poststratification weight was also used to make the sample distribution comparable with the population distribution in the 2001 South African census for age, gender, and province. The weighting and geographic clustering of the data were taken into account in data analyses by using the jackknife repeated replications simulation

a. Since the institutions in South Africa were once controlled along legally defined racial categories which separated 'Blacks' into 'Indians', 'Coloureds' and 'Africans', their daily experience and consequent psychiatric or physical health patterns could not be described without recourse to such racial terminology. The use of these terms in this paper does not imply their legitimacy. method implemented in an SAS macro. ${ }^{14}$ The survival coefficients were exponentiated and are reported below in the form of odds ratios.

\section{Results}

The estimated lifetime prevalence rates of suicide ideation, plans and attempts were $9.1 \%$ (s.e.=0.7), 3.8\% (s.e.=0.4) and $2.9 \%$ (s.e. $=0.3$ ) respectively. There were noticeable gender differences, with women reporting twice as many attempts as men: $3.8 \%$ (s.e. $=0.5) v .1 .8 \%$ (s.e. $=0.3$ ). The rate of attempted suicide varied significantly by ethnic group, with the Coloured group (of mixed racial origin) reporting levels $(7.1 \%$, s.e. $=1.3)$ that were markedly higher than that of the White $(2.4 \%$, s.e. $=0.7)$, Black $(2.4 \%$, s.e. $=0.3)$ and Indian groups $(2.5 \%$, s.e. $=1.6)$. There were also ethnic differences in the conditional probability of making an attempt among respondents with suicidal ideation but no plan. People classified as Black $(5.6 \%$, s.e. $=1.5)$ were less likely than those in the White $(10.0 \%$, s.e. $=3.7)$ and Indian $(27.0 \%$, s.e. $=29.0)$ groups to engage in impulsive suicide attempts, whereas those classified as Coloured $(33.4 \%$, s.e. $=9.6)$ reported the highest level of impulsive suicide attempts.

All of the DSM-IV disorders assessed in SASH were significant risk factors for a lifetime suicide attempt (Table DS1). Respondents with at least one DSM-IV disorder were four times (95\% CI 2.66.2) more likely to attempt suicide than those with no disorder. However, this result does not control for the main effects of individual disorders. All four summary variables for the diagnostic classes (e.g. any mood disorder, any anxiety disorder) were significantly associated with elevated risks of attempting suicide (ORs 3.0-4.1). The odds ratios for a substance use disorder $(\mathrm{OR}=4.1)$ increased the risk of a suicide attempt more than for any other disorder category (ORs 3.0-3.6). Among individual disorders the odds ratios for panic disorder $(\mathrm{OR}=8.9)$, alcohol abuse with dependence $(\mathrm{OR}=5.9)$ and drug use $(O R=5.0)$ were substantially higher than for other disorders, including depression or post-traumatic stress disorder (ORs 2.9-4.7).

The effects of comorbidity are presented in the final section of the data supplement table. Respondents with three or more disorders were eight times more likely to attempt suicide $(\mathrm{OR}=8.3$, 95\% CI 4.8-14.2) and to develop suicidal ideation ( $\mathrm{OR}=8.3,95 \%$ CI 4.3-15.8) than were respondents with no psychiatric disorder. Having three or more disorders was strongly associated with a higher risk of suicide attempts through the pathway of planned attempts $(\mathrm{OR}=2.9)$. The risks of attempts and of ideation were greater for respondents with two or more disorders than for those 
with no disorder, and substantially greater than the risks for those with only one disorder.

\section{Discussion}

The results reported here are limited by the fact that we do not know the extent to which mental health status or ethnic, cultural and generational factors affected the willingness of our respondents to admit or recall the presence of symptoms of suicide over their lifetime. There may also be bias associated with differential validity of the CIDI for the various ethnic groups in South Africa. Finally, the SASH is retrospective and cross-sectional; thus the prevalence estimates are likely to be lower-bound. ${ }^{4}$ However, the effect of most of these limitations would be to make our estimates of suicide behaviour more conservative than might be the case.

The $2.9 \%$ lifetime prevalence estimate of attempted suicide among the South African population is close to the rates of $4.6 \%$ and $4.1 \%$ reported for general and Black populations respectively in the USA. ${ }^{5,15}$ In addition, the $9.1 \%$ estimated prevalence of suicide ideation is comparable with previous estimates from studies using South African clinical samples. ${ }^{16,17}$ Reported for the first time are important ethnic differences among South Africans in the lifetime prevalence of suicide ideation, planning and attempts. Reasons for the substantially higher risk of attempted suicide and impulsive attempts among the Coloured group are unclear. 'Coloured' identity, historically and currently, has been fraught with conflict and contradictions. ${ }^{18,19}$ Our findings raise the possibility that people classified as Coloured may face unique stressors in their adjustment to rapid social transformation in a post-apartheid society. Prior research suggests that political and socio-economic transitions can adversely affect health. ${ }^{20,21}$ The mental health consequences of South Africa's rapid transitions should be carefully explored in future research. ${ }^{21,22}$

The SASH finding that psychiatric comorbidity is a significant predictor of suicide attempts over and above the effects of individual disorders is consistent with previous research on adult suicidal behaviour. ${ }^{4}$ In our sample we found that the suicide risks stay relatively constant when one disorder is present, increase in the presence of two disorders, and increase markedly for three or more disorders. Overall, these results suggest that people in South Africa engage in suicidal thought and behaviours at levels nearly comparable with those of Western nations. The higher rates of attempted suicide, notably among those categorised as Coloured, should be addressed in future research and considered by clinicians when screening and treating South African patients who might be suicidal.

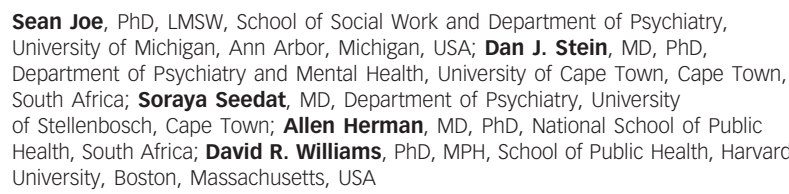

Correspondence: Dr Sean Joe, School of Social Work, University of Michigan 1080 South University Avenue, Room 2780, Ann Arbor, Michigan 48109, USA. Email: sjoe@ssw.umich.edu

First received 8 Mar 2007, final revision 17 Jun 2007, accepted 13 Jul 2007

\section{Acknowledgements}

The South Africa Stress and Health study was funded by grant R01-MH059575 from the National Institute of Mental Health (NIMH) and the National Institute of Drug Abuse, and funding from the South African Department of Health and the University of Michigan. It was carried out in conjunction with the World Health Organization World Mental Health
(WMH) Survey Initiative. We thank the WMH staff for assistance with instrumentation, fieldwork and data analysis. These activities were supported by the NIMH (R01MH070884), the John D. and Catherine T. MacArthur Foundation, the Pfizer Foundation, the US Public Health Service (R13-MH066849, R01-MH069864, and R01-DA016668), the Fogarty International Center (FIRCA R01-TW006481), the Pan American Health Organization, Eli Lilly, Ortho-McNeil Pharmaceutical, GlaxoSmithKline and Bristol-Myers Squibb. S.J. was supported by a grant (K01-MH65499) from NIMH and he is with the Program for Research on Black Americans in the Institute for Social Research, University of Michigan.

\section{References}

1 Charasse-Pouélé $C$, Fournier M. Health disparities between racial groups in South Africa: a decomposition analysis. Soc Sci Med 2005; 62: 2897-914.

2 World Health Organization. World Health Report 2003: Shaping the Future. WHO, 2003

3 Mann JJ, Apter A, Bertolote J, Beautrais A, Currier D, Haas A, Hegerl U, Lonnqvist J, Malone K, Marusic A, Mehlum L, Patton G, Phillips M, Rutz W, Rihmer Z, Schmidtke A, Shaffer D, Silverman M, Takahashi Y, Varnik A, Wasserman D, Yip P, Hendin H. Suicide prevention strategies. JAMA 2005; 294: $2064-74$

4 Kessler RC, Borges G, Walters EE. Prevalence of risk factors for lifetime suicide attempts in the National Comorbidity Survey. Arch Gen Psychiatry 1999: 56: 617-26.

5 Kessler RC, Berglund P, Borges G, Nock M, Wang PS. Trends in suicide ideation, plans, gestures, and attempts in the United States, 1990-1992 to 2001-2003. JAMA 2005; 293: 2487-95.

6 Snowdon J, Hunt GE. Age, period and cohort effects on suicide rates in Australia, 1919-1999. Acta Psychiatr Scand 2002; 105: 265-70.

7 Pritchard C, Hansen L. Comparison of suicide in people aged 65-74 and 75+ by gender in England and Wales and the major Western countries 19791999. Int J Geriatr Psychiatry 2005; 20, 17-25

8 Schlebusch L. Suicidal Behaviour in South Africa. University of KwaZulu-Natal Press, 2005.

9 The WHO Mental Health Survey Consortium. Prevalence, severity, and unmet need for treatment of mental disorders in the World Health Organization World Mental Health Surveys. JAMA 2004; 291: 2581-90.

10 Williams DR, Herman A, Kessler RS, Sonnega J, Seedat S, Stein DJ, Moomal H, Wilson $\mathrm{CM}$. The South Africa Stress and Health Study: rationale and design. Metab Brain Dis 2004; 19: 135-47.

11 Kessler RC, Ustun TB. The World Mental Health (WMH) survey initiative version of the World Health Organization (WHO) Composite International Diagnostic Interview (CIDI). Int J Methods Psychiatr Res 2004; 13: 93-121.

12 American Psychiatric Association. Diagnostic and Statistical Manual of Mental Disorders (4th edn) (DSM-IV). APA, 1994.

13 Efron B. Logistic regression, survival analysis, and the Kaplan-Meier curve. J American Sociological Association 1988; 83: 414-25.

14 Kish L, Frankel MR. Balanced repeated replications for standard errors. J Am Stat Assoc 1970; 65: 1071-94.

15 Joe S, Baser R, Breeden G, Neighbors HW, Jackson JS. Prevalence of and risk factors of lifetime suicide attempts among Blacks in the United States. JAMA 2006; 296: 2112-23.

16 Deonarain M, Pillay BJ. A study of parasuicide behaviour at the Chris Hani Baragwanath Hospital. In Suicidal Behaviour 4: Proceedings of the Fourth Southern African Conference on Suicidology (eds L. Schlebusch \& B. A. Bosch), pp. 112-27. Department of Medically Applied Psychology, University of Natal, 2000.

17 Schlebusch L. Current perspectives on suicidal behaviour in South Africa. In Crime, Violence and Injury Prevention in South Africa: Developments and Challenges, 9-21 (eds S. Suffla, A. van Niekerk \& D. Duncan). Medical Research Council/UNISA Crime, Violence and Injury Lead Programme, 2004.

18 Goldin I. Making Race: The Politics and Economics of Coloured Identity in South Africa. Longman, 1987.

19 Bookwalter JT, Dalenberg D. Subjective well-being and household factors in South Africa. Soc Indic Res 2004; 65: 333-53.

20 Yen IH, Syme SL. The social environment and health: a discussion of the epidemiologic literature. Annu Rev Public Health 1999; 20, 287-308.

21 Burrows S, Laflamme L. Suicide mortality in South Africa: a city-level comparison across socio-demographic groups. Soc Psychiatry Psychiatr Epidemiol 2006; 41: 108-14.

22 Burrows S, Vaez M, Butchart A, Laflamme L. The share of suicide in injury deaths in the South African context: sociodemographic distribution. Public Health 2003; 117: 3-10. 